\title{
RUMOR, INTIMIDADE E A VIDA QUE TRANSBORDA DAS PALAVRAS DE VEENA DAS
}

DAS, Veena. Vida e palavras: a violência e sua descida ao ordinário. Tradução bruno Gambarotto. São Paulo: Editora Unifesp, 2020. 312p.

“(...) um encontro com a dor não é uma transação simples ou que se resolva de uma vez só” (p.131)

$\mathrm{L}$ evei No seu Pescoço, o livro de contos da Chimamanda Adichie, para me acompanhar na espera por uma consulta. Abri sem pensar "Uma experiência privada". $\mathrm{Na}$ curta história, duas mulheres se abrigam em uma loja abandonada e empoeirada durante uma onda de violência dos hausa muçulmanos contra os igbo cristãos na Nigéria. Em meio aos tumultos, uma feirante hausa - de quem não saberemos o nome - salva Chika, estudante de medicina igbo, de correr para o lado dos ataques. As duas passam o dia juntas, escondidas. Medo, barulhos, resquícios de cenas de horror, lembranças doces, preocupação, perda de parentes e intimidades trocadas marcam as cenas que se formam na nossa cabeça.

Lembro de ter sido suspendida. Pela história, claro, mas também pela delicadeza e excepcional talento de escrita em desenhar personagens tão vivas, experimentando um dia em que o cotidiano foi devastado, mas que, ao mesmo tempo, continuava insistindo em seguir seu rumo. O mundo e suas 
ambivalências transbordam por meio das palavras da autora. Permaneci tocada pela complexidade de cada personagem, ainda por como eventos assim refazem a história e as reformulações da violência colonial. E, ao serem contados a partir da vida (mesmo que fictícia) de mulheres que os habitaram enquanto aconteciam, ou continuam experimentando suas lembranças, o tom ganha profundidade - marca a gente. Chimamanda tem essa genialidade no que escreve - Veena Das também.

O Livro Vida e Palavras, traduzido para o português com esmero por Bruno Gambarotto em 2020, fala sobre muitas coisas. Mas, em essência, é um livro sobre encontros com a violência, e sobre a vida acontecendo: “(...) como o evento se prende, com seus tentáculos, à vida cotidiana, e penetra os recessos do ordinário" (2020:22), é a forma como Das bem autodefine seu esforço. Esforço esse que envolve um justo mapeamento da literatura, um diálogo afiado com filosofia e teoria antropológica, e uma etnografia de fôlego - que dá espaço para as formulações filosóficas de seus interlocutores.

O livro abre com o prefácio escrito por Stanley Canvell, estudioso da obra de Wittgenstein, assim como Das. O autor sublinha alguns dos "achados" de Das, chamando especial atenção para como a sua curiosidade sobre a dor e o sofrimento humano a levam a dialogar com questões caras a Wittgenstein: o ceticismo e a possibilidade que as palavras/linguagem tem de estranhar e compor o familiar. Além, claro, do interesse filosófico centrado no ordinário, no que se faz no dia a dia e em como a reflexão do que é ser (e ser reconhecido como) humano, ou fazer parte de uma comunidade, pode emergir e se despedaçar a partir desse lugar.

O capítulo primeiro, "O evento e o cotidiano", situa o livro, seus temas, termos e preocupações. Deixa evidente a posição da autora em relação à etnografia. Em algum sentido, o livro é uma narrativa autobiográfica e conta como o conhecimento e a dor de outras pessoas marcaram Das. A autora lida com dois eventos: a Partição da Índia em 1947 e o assassinato da primeira ministra Indira Gandhi, em 1984. Mas não se trata, como faz questão de sublinhar, da narração objetiva de tais eventos, e sim de como sujeitos lidam com a presença e os resquícios desses eventos em seus cotidianos. A preocupação com a escala da narrativa é essencial. O sujeito é seu limite. Como Wittgenstein, o sujeito é tomado como o limite de um mundo. Das quer localizar o sujeito e seus limites e refletir sobre 
questões do tipo: "Como alguém habita o mundo?" "Como alguém perde o próprio mundo?”. A relação tentacular de eventos violentos com o fracasso da "gramática do cotidiano" são temas para ela. Voz e cotidiano são as categorias que maneja para tanto.

O capítulo "A figura da mulher raptada: o cidadão sexuado" defende que o contrato social e a criação do estado indiano, nutrido dos eventos da Partição e do tensionamento das relações entre hindus e muçulmanos, se compôs a partir da contrapartida de um contrato sexual. O evento da Partição foi marcado por raptos e estupros de ambos os lados. A instauração/independência de ambos os estados - Indiano e Paquistanês - ocorreu a partir da negociação da devolução (de modo numericamente igualitário) de mulheres e crianças raptadas. As feituras legislativas da figura da "mulher raptada" e de "crianças raptadas", para Das, resumem os termos da soberania de um estado masculino. O Estado poderia reivindicar mulheres, defensor instituído da honra masculina, que se transfigurou em honra nacional. A recuperação, inclusive, deveria acontecer independente da vontade da mulher em ficar. Em resumo, para Das “(...) o estado não apenas abafou a voz de mulheres, mas reconheceu a relevância do seu sofrimento apenas para a inauguração da soberania" (2020:66).

No capítulo três "Linguagem e corpo: transações na construção da dor", Das investiga o trabalho genderificado do luto. Inicia com três ficções. Com uma narrativa de Wittgenstein aprende que a dor pode residir no corpo de outra pessoa. Com Rabindranath Tagore investiga como as pessoas se tornam cegas para a concretude dos seres humanos e seu sofrimento a partir de projetos de tradição e modernidade. Por fim, dialoga com a história Khol Do, de Sa'adat Hasan Manto, para pensar como a cura pode ser um tipo de relação com a morte. Ao observar o trabalho genderificado do luto, pensa como a Partição mudou os termos desse trabalho. As mulheres, que normalmente falavam muito para lidar com o luto, calaram, e esse silêncio guia o aprendizado de Das. Na Partição, apropriar-se do território do outro se transfigurou em apropriar-se do corpo de mulheres. Essas, assim, passaram a carregar marcas da violência. O silêncio em relação ao luto e dor parecia tentar reconfigurar essas marcas. As metáforas de beber e guardar dentro de si um veneno, estar grávida de uma dor que seria transformada no íntimo, dor que trazia perigo ao ser dita, compunham as falas. Diferente de estratégias que queriam "dar voz" às mulheres, ou 
contar as histórias de mulheres para que essas fossem ouvidas e reconhecidas, Das sugere que negar a dor do outro não é uma falha de intelecto a ser recuperada pela informação, mas uma falha de espírito. Sua estratégia, assim, é lidar com o silêncio e buscar caminhos para aprender como deixar a dor habitar outros corpos - transfigurar seus espíritos.

No capítulo "O ato de testemunhar: violência, gênero e subjetividade", Das investiga o que é ser sujeito na relação com o idioma cultural. O espaço de transgressão e assujeitamento e a lida ambígua com a morte são discutidas a partir da interpretação lacaniana de Antígona e das reflexões de uma mulher chamada Asha. O trabalho cotidiano de reparação é observado. Asha perde o marido e, como viúva, sua circulação entre a casa dos parentes é marcada pelos resquícios, traições e desconfianças deixados pela Partição. A estética das relações se perde, novas solidariedades surgem e há, ainda, um trabalho contínuo de recuperar relações. Essa recuperação das relações ocorre tanto pela transgressão das normas locais e abertura de narrativas alternativas de subjetividade, como pela reivindicação das relações a partir da própria defesa da cultura. Em alguma medida, Das entende que o luto envolve habitar o mundo, refazê-lo.

No capítulo "Fronteiras, violência e o trabalho do tempo", a autora olha para a "pobreza de palavras" das mulheres sobre os eventos da Partição como uma forma de assegurar a própria humanidade. E não como falta de possibilidade de representar frente ao horror, saída comum à literatura. Nesse capítulo, conhecemos Manjit, uma mulher que foi raptada durante a Partição, voltou e casou-se com um homem mais velho. Havia muitas insinuações sobre Manjit ter ou não sido estuprada, mas nada era dito de forma aberta, nem pelos outros, nem por ela. Em alguma medida, o silêncio a protegia. A falta de linguagem compunha a experiência de Manjit. Mas as insinuações e a desconfiança do marido e de sua mãe, também eram mote de violências cotidianas - essas sim dizíveis. A raiva de Manjit, transferida ao seu filho primogênito, levou a ocorrência e gravidade de violências em casa e no afastamento da família. Com o tempo, contudo, violência e afastamento foram sendo resolvidos, amansados. O silêncio, para a história de Manjit, era fundamental, assim como o trabalho do tempo. Das insiste que as histórias sejam contadas no singular, que não se percam em narrativas de horror compartilhadas. 
O capítulo "Pensando o tempo e a subjetividade" é uma ponte entre os capítulos anteriores - que tematizam a Partição e os próximos capítulos, que tematizam os eventos que circundam o assassinato de Indira Gandhi. E a reflexão sobre temporalidade guia essa ponte. Para Das, a experiência cotidiana dos eventos torna difícil que sejam localizados em um período delimitado. A Partição vive no presente das pessoas, é dificil ainda saber quando os eventos envolvendo o assassinato de Indira Ganhi iniciaram ou terminaram. Das investiga, filosoficamente, como o passado se faz presente. Diferenciandose das narrativas do trauma e da eterna repetição histórica, observa a potência do rumor nesse trabalho de atualização da violência e do passado.

O capítulo seguinte, "Na região do rumor", dá seguimento a essa proposta. Para a autora "o rumor ocupa uma região da linguagem com o potencial de nos fazer experimentar eventos, não simplesmente assinalando-os como algo externo, mas produzindo-os no próprio ato de contar" (2020:151). A autora defende que os rumores conectaram certos eventos. A primeira ministra Indira Gandhi foi morta em 1984, por seguranças sikh. Antes da notícia ser confirmada, se iniciaram as especulações. Teria sido uma vingança pela operação militar do estado indiano contra o Templo Dourado, diziam os rumores. A militância sikh havia crescido nos anos 1980, contrapondo-se ao estado, nomeado majoritariamente hindu. Reivindicavam a falta de reconhecimento pelos sacrifícios do passado, feitos no período da Partição. Essa reivindicação se traçava no linguajar da masculinidade: a recuperação de uma masculinidade pura, sikh, afastada de homens hindus e de uma nação efeminada, que havia traído os sikh, apesar de ter dependido de sua potência e proteção no momento da fundação. $\mathrm{O}$ ataque ao Templo foi entendido como uma reação do estado indiano a tal militância: o assassinato da primeira ministra como vingança. Se seguiu o espalhar da notícia que a comunidade sikh estaria planejando um amplo ataque contra hindus. A conspiração foi composta ainda da desqualificação de práticas religiosas e afetos como "loucura sikh". Em poucas horas, se deu uma profunda desqualificação dos sikh, culminando na transformação desses em um outro sem rosto, perigoso genérico. Todos esses eventos participaram dos ataques ao povo sikh, descritos nos próximos capítulos.

No capítulo "A força do local", Das provoca narrativas oficiais sobre os assassinatos dos sikh e os ataques às suas comunidades que seguiram o assassinato de Indira Gandhi. 
Posicionada no momento de sua ocorrência como partícipe de um conjunto de voluntários dispostos a investigar a fundo os ataques e exigir atenção para que fossem interrompidos e para que os sobreviventes fossem protegidos e ressarcidos, a autora passou a montar uma narrativa alternativa. A narrativa comum pintava uma "multidão enfurecida", ou a agressividade de "elementos antissociais" cegos para vingar a morte de sua primeira ministra. Em contraponto, Das mostra a participação de funcionários estatais, policiais, grupos armados e políticos proeminentes na organização sistemática dos assassinatos para mobilizar apoio hindu e para punir os sikh. A autora desenha as histórias por meio de mapas, gráficos, contagens de mortos, histórias ouvidas sobre os eventos e documentos dos mais diversos. Situar-se em uma localidade: Saltampuri, é o que a permite observar muitas das nuances e escalas dos eventos.

No capítulo "A assinatura do estado: o paradoxo da ilegibilidade", Das observa o funcionamento do estado - um clássico tema para a autora. Discute como o estado oscila entre modos racionais e mágicos de ser. Mágico porque "têm consequências que são reais", "as forças mobilizadas não são transparentes" e porque "comprometer-se com a magia é colocar-se em posição de vulnerabilidade" (2020:220). Ao observar usos, transformações e acessos a documentos por parte da população que viveu os ataques, lida com a ilegibilidade dos modos de ser do estado, assim como com a sua intensa capilaridade na vida das pessoas. Como o rumor, a assinatura do estado está em todos os lugares.

No capítulo "Três retratos de dor e luto" Das nos conta a história do sofrimento e suicídio de uma mãe que perdeu seus filhos, Shanti, quem reformulava os eventos a partir da culpa e enlouquecimento, alimentada ainda por relações tensas entre parentes e vizinhos. Nos fala sobre o luto coletivo performado por mulheres que, ao recusarem o banho, a troca de roupas e os cabelos arrumados, perambulavam pelos escombros, fazendo com que o ocorrido fosse impossível de ser apagado. Nos leva ainda para a experiência de crianças, suas lembranças, curiosidade pelos noticiários, brincadeiras e elaborações.

O livro finaliza com o capítulo "Revisitando o trauma, o testemunho e a comunidade política". Das reflete sobre sua posição em campo, suas lidas com estado, ativismo local, dissimulações e ambiguidades para responder a tudo que lhe acontecia como antropóloga. A autora defende que a reflexividade sobre esses arranjos de pesquisa e política é o que 
pode afastar a antropologia de uma completa instrumentalização por parte de forças mágicas, como a do Estado e do mercado. Por fim, Das se posiciona novamente no sentido de não nomear a violência como trauma, fugindo da armadilha profética da constituição de "comunidades de ressentimento", fadadas a repetir a violência que as marcou. Insiste na potência de descer ao cotidiano para ver como eventos se criam e como as vidas se refazem na relação com morte e luto. Ainda defende um tipo de ética da responsabilidade para a antropologia - uma que recusa a cumplicidade com qualquer tipo de violência e que se abre para que a dor do outro possa lhe habitar, e que o perigo e refazimento dessa dor em si ensine o que, e como, contar.

O livro tem equilíbrio. Longe de se aproveitar de uma dicotomia opaca entre compor vítimas ou reforçar resistências, Das aposta na densidade das histórias, na intensa reflexividade de seus interlocutores sobre a sua dor, a violência dos outros e o fazimento da vida. Saí do livro suspensa, assim como saí do conto de Chimamanda. Os refazimentos da violência colonial, as monstruosidades que conhecidos podem fazer uns com os outros e a feitura de relações significativas, algumas delas a despeito de tudo - tudo isso marca quem lê. Talvez essa suspensão seja o que Das chama de deixar que a dor encontre morada em outros corpos. A estratégia narrativa funciona de modo delicado, progressivo, genial. Como sintetiza Achille Mbembe na contracapa, o livro é "brilhante e profundo", o "auge da aclamada carreira de Veena Das".

\section{Referência bibliográfica}

ADICHIE, Chimamanda. 2017. "Uma experiência privada". In: Chimamanda Adichie. No seu pescoço. São Paulo: Companhia das Letras. p. 50-63.

Enviado: 1 de dezembro de 2020

Aceito: 15 de dezembro de 2020 